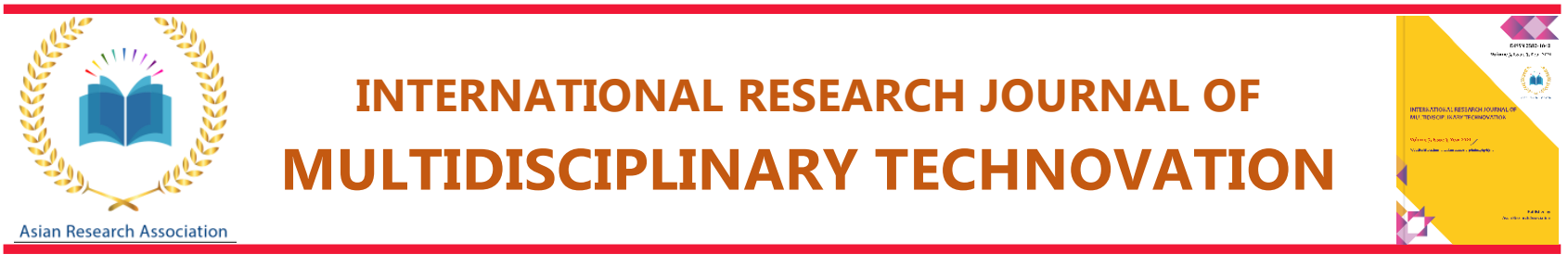

\title{
Modeling and Optimization of Gas-Solid Fluidization of Binary Mixtures using Box-Behnken Experimental Design
}

\author{
K.M. Abd Ali ${ }^{1}$, A.N. Ghanim 1, ${ }^{*}$ \\ ${ }^{1}$ Department of Chemical Engineering, College of Engineering, Babylon University, Iraq. \\ *Corresponding authors email: ala gh2003@yahoo.com \\ DOI: https://doi.org/10.54392/irjmt2163 \\ Received: 07-05-2021, Revised: 29-10-2021; Accepted: 03-11-2021, Published: 15-11-2021
}

Abstract: The influence of different factors on the fluidization of a binary mixture of red mud and aluminum was investigated. A new model was developed for predicting pressure drop through the solid bed using experimental data of other work. Statistical analysis based on response surface methodology has been used to develop correlations for bed pressure drop with three independent factors, minimum fluidization velocity $\left(U_{m f}\right)$, red mud to aluminum ratio $(R / A)$, and static head $\left(H_{s}\right)$. The design of experiments offers a best alternative to study the effect of factors and their response with the minimum number of experiments. The hydrodynamic characteristics of fluidization, bed pressure drop, superficial gas velocity $\left(U_{m f}\right)$, red mud to aluminum ratio $(R / A)$, and initial static bed height $\left(H_{s}\right)$ were modeled and optimized. ANOVA has been used to analyze the system parameters on bed pressure drop. A model of bed pressure drop was found to have a correlation coefficient of 0.98 . The measured values of bed pressure drop from RSM were found to match the experimental values very well.

Keywords: Fluidized bed, Static bed height, RSM, Model, ANOVA, Minimum fluidization velocity

\section{Introduction}

The phenomenon of fluidization occurs when solid particles are suspended in an upward flowing fluid and the suspension behaves like a pseudofluid [1]. The minimum fluidization velocity is an important hydrodynamic feature of FBS because it indicates when particles begin to fluidize from a packed state [2, 3]. The use of fluidized beds allows for a high degree of solid phase distribution homogeneity as well as high mass and heat exchange efficiency. In fact, the solid's division provides a large surface area for exchanges, and particle agitation accelerates the transfer process.

Many theoretical models $[4,5]$ were developed for minimum fluidization velocity and bed pressure drop for spherical particles for gas-solid systems in conical vessels. In addition, several correlations were used for the fine tailings materials that comprise a variety of constituents and possess a degree of cohesiveness [6].

Fluidization is the favored method of operation because of its various advantages over other setups, including: strong solid mixing resulting in uniform temperature in the bed, high mass and heat transfer rates, simple solids handling, ability to maintain a uniform temperature, substantially lower pressure drops resulting in lower pumping costs, and lower investments for fluidization equipment [7].

The aim of this research was to specify the important factors that influence the pressure drop of a binary mixture. ANOVA has been used to analyze the individual and interaction effects of system parameters on bed pressure drop. A numerical optimization was used to find a point that maximizes the desirability function.

\section{Experimental set-up}

The experiments were carried out in cylindrical glass column as shown in Figure (1). The height of the cylindrical column is $150 \mathrm{~cm}$ and diameter of the column is $10 \mathrm{~cm}$. To keep particles from falling down, the distribution plate is covered with a fine-mesh net. Pressure measurements were taken at the bed axis using supported steel probe. For the investigation, two types of materials were used: red mud and aluminum. The mixture of red mud to Al was taken into different ratios as, $4: 1,3: 1,3: 2$ and 1:1. The bed was filled with type (A) particles [8] with a mean diameter and density as mentioned in Table (1). The air flow rate was measured with a rotameter. The volumetric flow rates 
ranged from $0-10 \mathrm{~L} / \mathrm{min}$, resulting in a fluidizing velocity of $0-0.8 \mathrm{~m} / \mathrm{s}$.

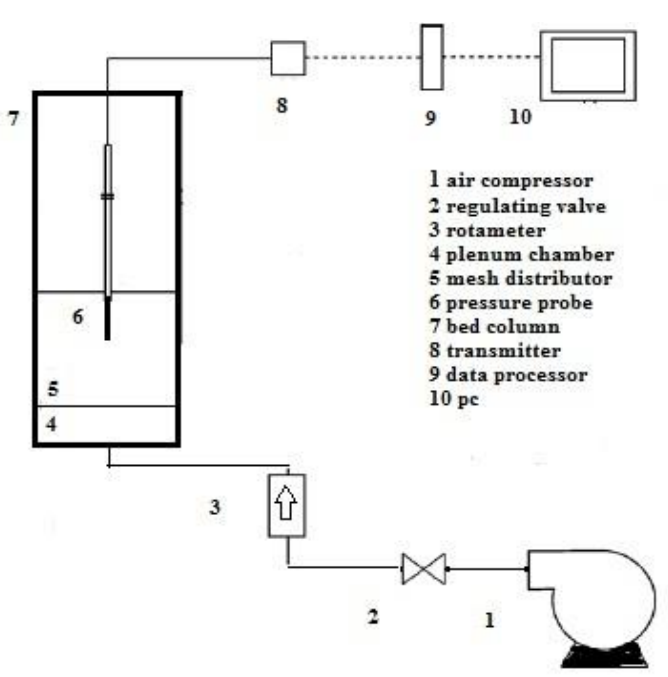

Figure 1. Schematic diagram of fluidized bed apparatus.

Table 1. Physical properties of solid mixture ratio used in the present study [9].

\begin{tabular}{|l|l|l|l|l|}
\hline Particle & $\begin{array}{l}\text { Avg. } \\
\text { density } \\
\rho s \mathrm{~kg} / \mathrm{m}^{3}\end{array}$ & $\begin{array}{l}\text { Avg. } \\
\text { particle } \\
\text { size dp, } \\
\text { microns }\end{array}$ & $\begin{array}{l}\text { umf, } \\
\mathrm{m} / \mathrm{s}\end{array}$ & $\begin{array}{l}\mathrm{ut}, \\
\mathrm{m} / \mathrm{s}\end{array}$ \\
\hline Only red mud & 3000 & 63 & 0.0275 & 0.29 \\
\hline RM:Al (4:1) & 2940 & 150.4 & 0.153 & 1.1 \\
\hline RM:Al (3:1) & 2925 & 172.5 & 0.201 & 1.31 \\
\hline RM:Al (3:2) & 2880 & 237.8 & 0.376 & 1.887 \\
\hline RM:Al (1:1) & 2850 & 281.5 & 0.52 & 2.23 \\
\hline
\end{tabular}

\section{Methodology}

Statistical analysis is based on response surface methodology has been used to develop correlations for pressure drop with three independent factors, minimum fluidization superficial velocity $\left(U_{m f}\right)$, red mud to aluminum ratio $(R / A)$, and static head $\left(H_{s}\right)$. The design of experiments offers a better alternative to study the effect of factors and their response with the minimum number of experiments. This set-up allowed the development of empirical model equation as a function of minimum fluidization superficial velocity $\left(U_{m f}\right)$, red mud to aluminum ratio $(R / A)$, and static head $\left(H_{s}\right)$ in linear and quadratic effect terms. The BoxBehnken design, an experimental design for RSM, was used to create a set of designed experiments by Design-Expert software version 7.0.3. The properties of simulated model were presented in Table (2).
Table 2. Data of Box-Behnken experimental design for pressure drop evaluation

\begin{tabular}{|l|l|l|l|lr|}
\hline Run No. & $U_{m f}$ & $R / A$ & $H_{s}$ & \multicolumn{2}{|l|}{$\Delta P\left(\mathrm{~N} / \mathrm{m}^{2}\right)$} \\
\cline { 5 - 6 } & $(\mathrm{m} / \mathrm{s})$ & & $(\mathrm{cm})$ & Exp. & Pred. \\
\hline 1 & 0.27 & 2.0 & 4.9 & 4350 & 4254 \\
\hline 2 & 0.27 & 1.0 & 4.0 & 3821 & 3252 \\
\hline 3 & 0.50 & 3.0 & 4.9 & 10450 & 10472 \\
\hline 4 & 0.27 & 2.0 & 4.9 & 4400 & 4254 \\
\hline 5 & 0.04 & 2.0 & 4.0 & 2807 & 3398 \\
\hline 6 & 0.04 & 2.0 & 5.8 & 2490 & 2895 \\
\hline 7 & 0.50 & 2.0 & 5.8 & 16860 & 16279 \\
\hline 8 & 0.27 & 2.0 & 4.9 & 4320 & 4254 \\
\hline 9 & 0.50 & 2.0 & 4.0 & 4570 & 4165 \\
\hline 10 & 0.27 & 3.0 & 4.0 & 3840 & 4222 \\
\hline 11 & 0.27 & 2.0 & 4.9 & 4310 & 4254 \\
\hline 12 & 0.50 & 1.0 & 4.9 & 6470 & 7443 \\
\hline 13 & 0.27 & 1.0 & 5.8 & 9630 & 9248 \\
\hline 14 & 0.27 & 2.0 & 4.9 & 3890 & 4254 \\
\hline 15 & 0.04 & 3.0 & 4.9 & 2120 & 1147 \\
\hline 16 & 0.27 & 3.0 & 5.8 & 9260 & 9828 \\
\hline 1 & 0.04 & 1.0 & 4.9 & 2650 & 2627 \\
\hline
\end{tabular}

There were three first-order effects (terms in $U_{m f}, R / A$ and $H_{s}$ ), three interaction effects (terms in $U_{m f .} R / A, U_{m f} . H_{s}$ and $\left.R / A . H_{s}\right)$, and three second-order effects $\left(U_{m f^{2}},(R / A)^{2}\right.$ and $\left.H s^{2}\right)$, The response has been used to develop an empirical model by statistical analysis that correlates the response of fluidized bed with process factors using a second-degree polynomial equation $[10,11]$ as given by Eq. (1).

$Y=b_{0}+\sum_{i=1}^{k} b_{i} x_{i}+\sum_{i=1}^{k} b_{i i} x_{i}^{2}+\sum_{i=1}^{k} \sum_{j=i+1}^{k} b_{i j} x_{i} x_{j}$

Where $Y$ is the predicted response used as a dependent factor, $k$ is the number of independent factors, $x_{i}(i=1,2)$ the controlling factors; $b_{0}$ the constant coefficient, $b_{i}, b_{i i}$ and $b_{i j}$ the coefficients of linear, quadratic and interaction terms, respectively.

The predicted response $(Y$ ) was correlated therefore to the set of regression coefficients (10 coefficients). Selection of the experiment factor levels was carried out based on the effective pressure drop response, where the minimum fluidization superficial velocity level of $0.04-0.5 \mathrm{~m} / \mathrm{s}$, red mud to aluminum particle ratio level (1:1-3:1), and static head level of 4$5.8 \mathrm{~cm}$, were conducted the experimental set. In this sense, a total of 17 runs might have to be established if 
general factorial design is used for the prediction of response.

A series of 17 experiments for reliable measurement of bed pressure drop response were designed, with design of unblocked and 5 replicate. Analysis of variance (ANOVA) was used for graphical analysis of data to obtain the interaction between factors and response. The quality of the fit polynomial model was expressed by the regression coefficients $R^{2}$, and its statistical significance was checked by the Fisher's F-test [10].

The model parameters were evaluated by the p-value (probability) with 95\% confidence level. The coefficient of parameters were estimated using response surface regression analysis employing the Minitab software version 14, also used to find the residuals, 3D surface and $2 \mathrm{D}$ contour plots of the response models.

\section{Results and discussion}

\section{Regression model}

An empirical model was developed to calculate the bed pressure drop of a binary mixture in two-phase fluidized bed, as shown in Table (3), using statistical software package design experts. The analysis of experimental data revealed that the response can be influenced by the initial static bed height, minimum fluidization velocity, and solid mixture ratio.

The relationship between the independent factors and the response for pressure drop was analyzed using response surface methodology (RSM). The Box-Behnken design shown in Table (3), allowed the development of second order polynomial equation, where presser drop was assessed as a function of minimum fluidization superficial velocity, red mud/aluminum ratio, and static head of column. Experimental response data were used to conduct a quadratic regression model using response surface methodology [10]: The following equation has been obtained for pressure drop.

$$
\begin{aligned}
& \Delta P=62348.1-75228.3 A-22710.2 C+ \\
& 4902.2 A B+15225.8 A C+2248.7 C^{2}
\end{aligned}
$$

The "Pred $R^{2 "}$ of 0.73 is not as close to the "Adj $R^{2 \prime}$ of 0.96 as one might normally expect. This may indicate a large block effect or a possible problem with the model and/or data. Things to consider are model reduction, response transformation, outliers, etc.

\begin{tabular}{|c|c|c|c|c|c|c|}
\hline Source & Sum of squares & Degree of freedom & Mean square & F value & \multicolumn{2}{|c|}{ P-value Prob $>F$} \\
\hline Model & $2.314 \mathrm{E}+8$ & 9 & $2.572 \mathrm{E}+7$ & 44.68 & $<0.0001$ & Significant \\
\hline$A(U m f)$ & $9.999 \mathrm{E}+7$ & 1 & $9.999 \mathrm{E}+7$ & 173.74 & $<0.0001$ & Significant \\
\hline$B(R / A)$ & $1.200 \mathrm{E}+6$ & 1 & $1.200 \mathrm{E}+00$ & 62.09 & 0.1919 & Insignificant \\
\hline$C(H s)$ & $6.729 \mathrm{E}+7$ & 1 & $6.729 \mathrm{E}+7$ & 116.92 & $<0.0001$ & Significant \\
\hline$A B$ & $5.085 \mathrm{E}+6$ & 1 & $5.085 \mathrm{E}+6$ & 8.84 & 0.0207 & Significant \\
\hline$\overline{A C}$ & $3.973 \mathrm{E}+7$ & 1 & $3.973 E+7$ & 69.04 & $<0.0001$ & Significant \\
\hline$B C$ & 37830.25 & 1 & 37830.25 & 69.04 & 0.8050 & Insignificant \\
\hline$A^{2}$ & $1.548 \mathrm{E}+6$ & 1 & $1.548 \mathrm{E}+6$ & 2.69 & 0.1451 & Insignificant \\
\hline$B^{2}$ & $1.331 \mathrm{E}+6$ & 1 & $1.331 \mathrm{E}+6$ & 2.31 & 0.1721 & Insignificant \\
\hline$C^{2}$ & $1.397 \mathrm{E}+7$ & 1 & $1.397 \mathrm{E}+7$ & 24.27 & 0.0017 & Significant \\
\hline Residual & $4.029 \mathrm{E}+6$ & 7 & $5.755 E+5$ & & & \\
\hline Lack of Fit & $3.858 \mathrm{E}+6$ & 3 & $1.286 \mathrm{E}+6$ & 30.17 & & \\
\hline Pure Error & $1.705 \mathrm{E}+5$ & 4 & 42630 & & & \\
\hline Cor Total & $2.355 \mathrm{E}+8$ & & & 16 & & \\
\hline$R^{2}$ & 0.9829 & & & & & \\
\hline $\operatorname{Adj~} R^{2}$ & 0.9609 & & & & & \\
\hline Pred $R^{2}$ & 0.7367 & & & & & \\
\hline Adeq Precision & 25.99 & & & & & \\
\hline
\end{tabular}

Table 3. ANOVA of response surface quadratic model of bed pressure drop 


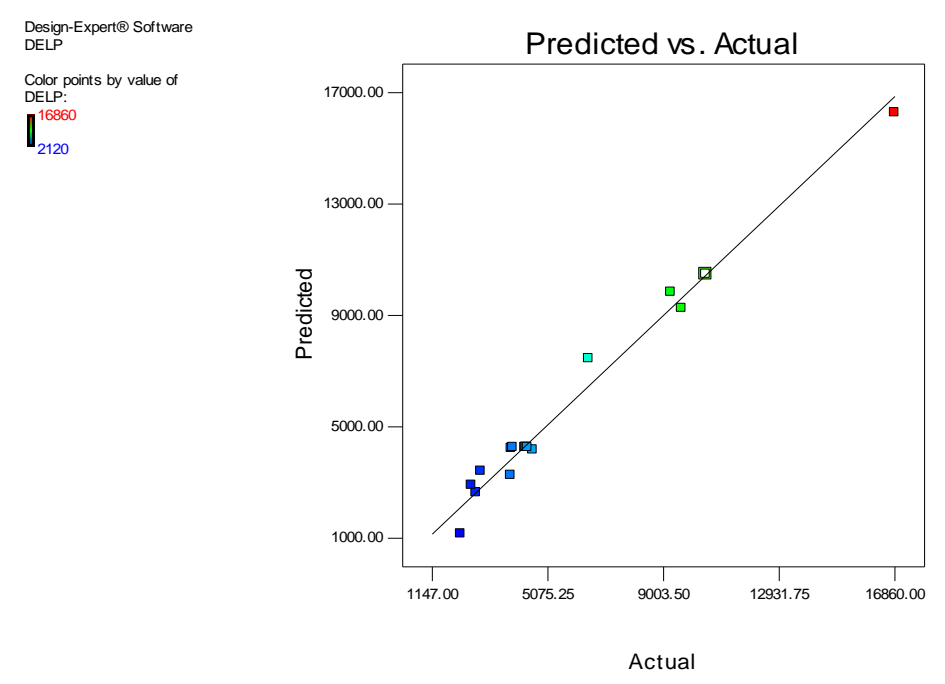

Figure 2. A comparison of predicted and experimental pressure drop values using Eq. (2)

"Adeq Precision" measures the signal to noise ratio. A ratio greater than 4 is desirable. Ratio of 25.99 indicates an adequate signal. This model can be used to navigate the design space.

A model F-value of 44.68 implies that the model is significant. There is only a $0.01 \%$ chance that a "Model F-Value" this large could occur due to noise. Values of "Prob > $F$ " less than 0.05 indicate model terms are significant. In this case values greater than 0.1 indicate the model terms are not significant. If there are many insignificant model terms (not counting those required to support hierarchy, model reduction may improve your model. The "Lack of Fit F-value" of 30.17 implies the Lack of Fit is significant. There is only a $0.33 \%$ chance that a "Lack of Fit F-value" this large could occur due to noise.

Analysis of variance (ANOVA) for the response of $\Delta P$ is represented in Table (3). The results show that the statistical terms (sum of squares, degree of freedom, $F$-value, and $p$-value) of regression, values of $p<0.05$ indicate that the model terms are significant, hence $A, C, A B, A C, C^{2}$ are significant model terms, however the insignificant terms are the linear term $B$ ratio and the quadratic terms $B C, A^{2}$, and $B^{2}$ of $\mathrm{p}$ values more than 0.05 , so the insignificant terms were rejected to improve and support model fitness.

\section{Validity of the model}

Eq. (2) was validated by comparing the response values estimated from the models with the response experiment values for various binary mixture values. Figure (2) compares the model output of pressure drop through the binary mixture bed of $R / A$ ratio with experimental data. Eq. (2) predicted the pressure drop with sufficient accuracy. As shown in Figure (2), the predicted values obtained using the model equation were found to be in good agreement with the experimental values with a 96 percent confidence level.

The correlation coefficient $\left(R^{2}\right)$, adjusted correlation coefficient $\left(R^{2} a d\right)$, and predicted correlation coefficient ( $R^{2}$ pred) for Eq. (2) are $96 \%, 94 \%$, and $74 \%$, respectively, which demonstrate that the developed model for bed parameters and ratios agrees well with the experimental values. There is some deviation between the values of $R^{2}$ adj and $R^{2}$ pred. This may be due to some insignificant model terms and the nonlinear behavior of the model.

\section{Model Graphs}

\section{Three-D Surface Graphs}

The pressure drop in fluidization process plays an important role in the design of a fluidized bed and is greatly affected by minimum fluidization velocity $\left(U_{m f}\right)$, solid mixture ratio, and bed design. Both the individual and combined effect of operating factors such as minimum fluidization superficial velocity $\left(U_{m f}\right)$, red mud to aluminum ratio $(R / A)$, and static head $\left(H_{s}\right)$ were studied using RSM.

Figures (3-5) show the combined effects of the three factors namely, minimum fluidization superficial velocity $\left(U_{m f}\right)$, red mud to aluminum ratio $(R / A)$, and static head $\left(H_{s}\right)$, on bed pressure drop. The combined effect of minimum fluidization velocity and static bed height is shown in Figure (3). The bed pressure drop decreases while the superficial gas velocity increases. This could be because as the gas velocity increases, so does the gas hold up, lowering the density of the mixture. Increases in solid density may also increase the buoyancy force, lowering the drag of the shape and, as a result, the bed pressure. Figure (3) also 
shows that as the initial static bed height is increased, the bed pressure increases to counterbalance the weight of the bed.

As shown in Figure (3), the minimum fluidization velocity $\left(U_{m f}\right)$ and static bed height $\left(H_{s}\right)$ are both direct functions of pressure drop decrease. Because the weight of the bed increases as the static bed height and particle size increase, so does the pressure drag.

The combined effect of minimum fluidization superficial velocity $\left(U_{m f}\right)$ and red mud to aluminum ratio
$(R / A)$ on bed pressure drop is depicted in Figure (4). The Figure shows that the bed pressure increases as the minimum fluidization velocity increases, while it decreases as the $(R / A)$ ratio increases.

Similar trends can be observed in Figure (5), which represents the combined effect of initial static bed height $\left(H_{s}\right)$ and red mud aluminum ratio $(R / A)$ on bed pressure drop. It has been found that as the initial static bed height $\left(H_{s}\right)$ and the red mud to aluminum ratio $(R / A)$ decrease, so does bed pressure drop.

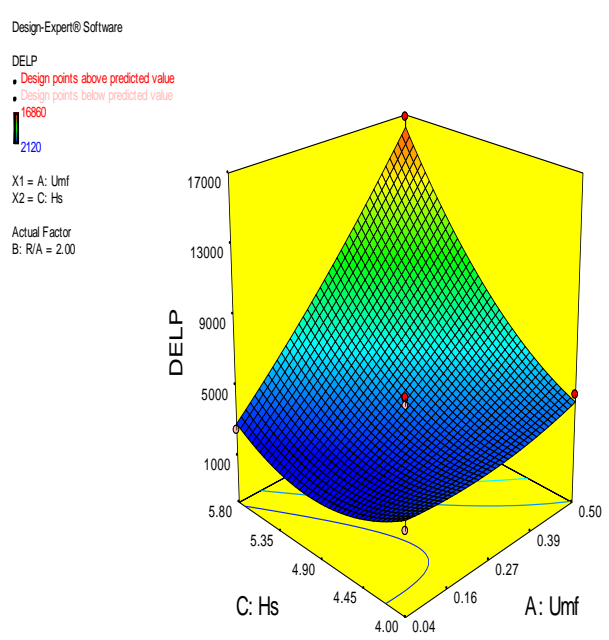

Figure 3. Response surface of bed pressure drop as a function of minimum fluidization velocity and static bed height

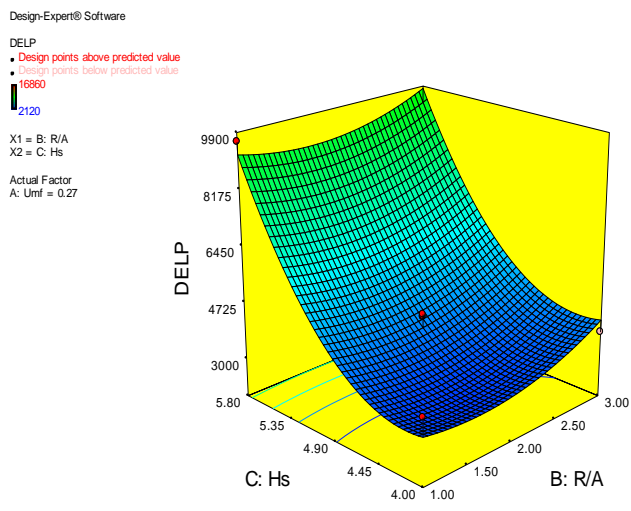

Figure 5. Response surface of bed pressure drop as a function of initial static head and red mud to aluminum ratio

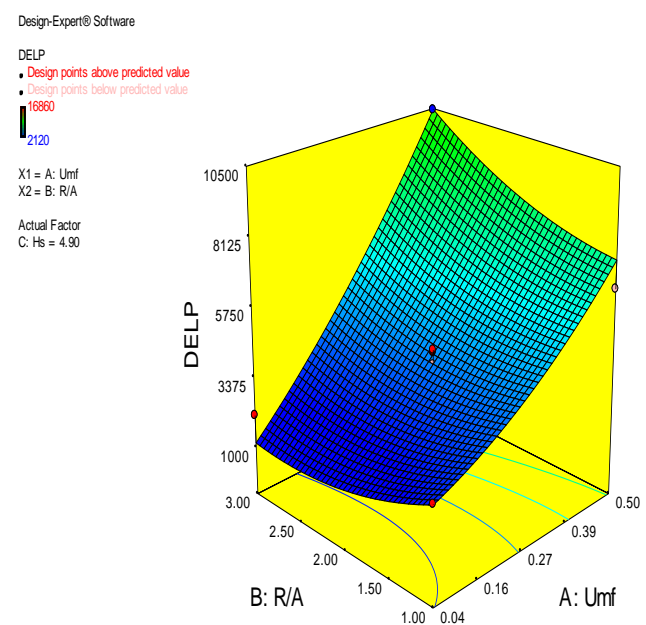

Figure 4. Response surface of bed pressure drop as a function of minimum fluidization velocity and red mud to aluminum ratio
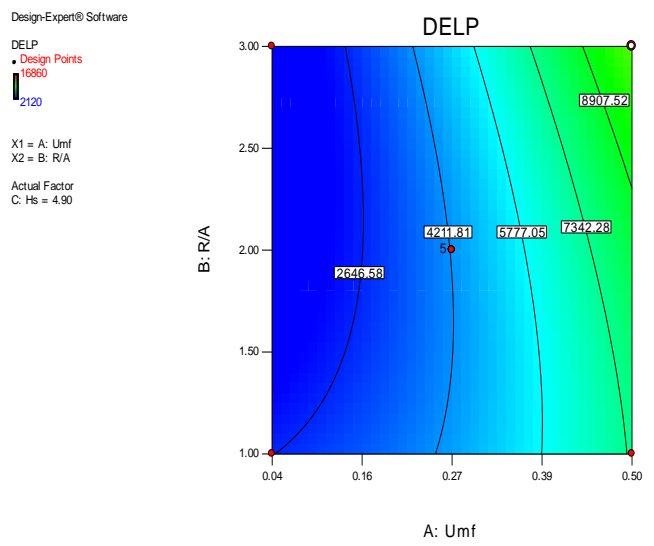

Figure 6. Effect of minimum fluidization velocity and red mud aluminum ratio on bed pressure drop 

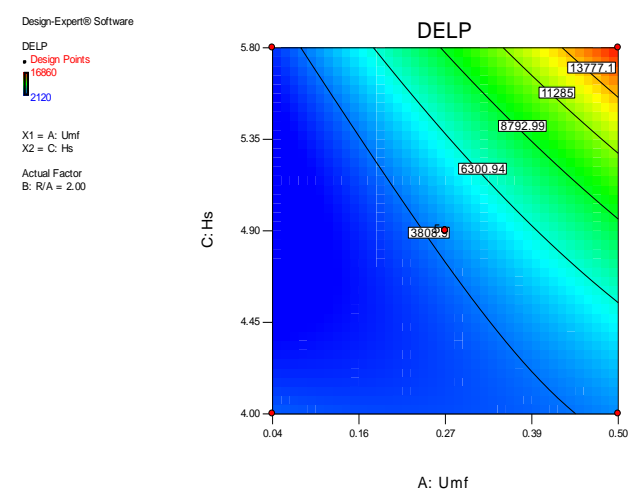

Figure 7. Effect of initial static bed height and minimum fluidization velocity on bed pressure drop

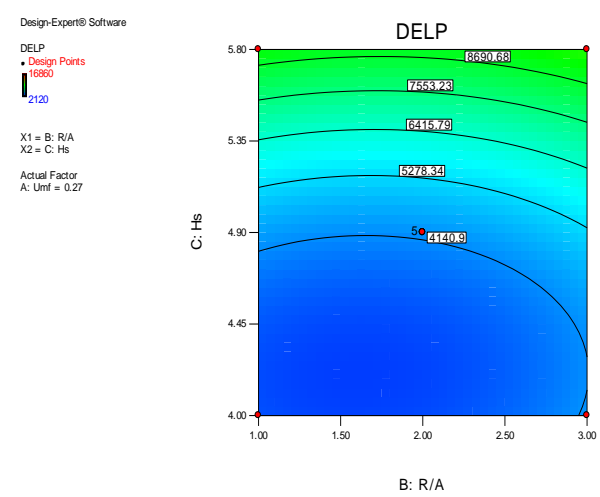

Figure 8. Effect of initial static bed height and redmud Aluminum ratio on bed pressure drop

Table 4. Constrains of numerical optimization

\begin{tabular}{|l|l|l|l|l|l|l|}
\hline Parameter & Goal & Lower limit & Upper limit & Lower weight & Upper weight & Importance \\
\hline $\mathrm{U}_{\mathrm{mf}}$ & in range & 0.04 & 0.5 & 1 & 8 & 3 \\
\hline $\mathrm{R} / \mathrm{A}$ & in range & 1 & 5 & 1 & 1 & 3 \\
\hline $\mathrm{Hs}$ & minimize & 4 & 5.8 & 1 & 1 & 3 \\
\hline DELP & minimize & 2120 & 16860 & 1 & 1 & 5 \\
\hline
\end{tabular}

Table 5. The optimum bed pressure drop conditions based on numerical optimization

\begin{tabular}{|l|l|l|l|l|}
\hline $\mathrm{U}_{\mathrm{mf}}$ & $\mathrm{R} / \mathrm{A}$ & $\mathrm{Hs}$ & DELP & Desirability \\
\hline 0.38 & 1.00 & 4.00 & 3036.72 & 0.961 \\
\hline
\end{tabular}

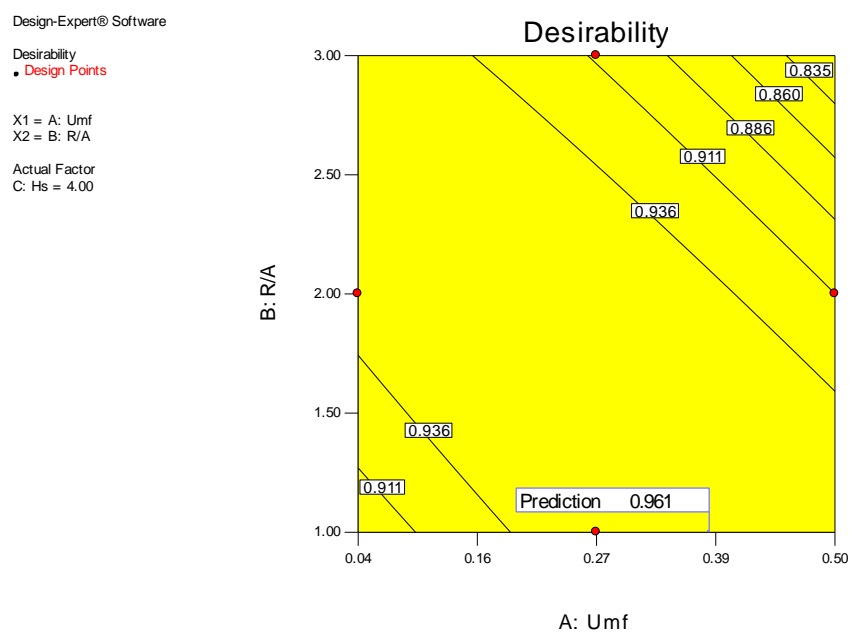

Figure 9. Desirability for optimum parameters

\section{Contour Charts}

The contour chart is a two-dimensional representation of the response to various factors. Figure (6) shows the combined effect of solid mixture ratio $(R / A)$ and minimum velocity $\left(U_{m f}\right)$ on bed pressure drop. It has been found that as the $\left(U_{m f}\right)$ velocity increases, so does the bed pressure drop, whereas as the $(R / A)$ ratio increases, so does the bed pressure drop. 
The combined effect of initial static bed $\left(H_{s}\right)$ and minimum velocity $\left(U_{m f}\right)$ on bed pressure drop is shown in Figure (7). Similarly, it has been observed that as $\left(U_{m f}\right)$ velocity and $\left(H_{s}\right)$ increase, so does the bed pressure drop. Using contour lines, Figure (8) shows the combined effect of initial static bed $\left(H_{s}\right)$ and $(R / A)$ ratio on bed pressure drop. The bed pressure drop increases as the solid mixture ratio $(R / A)$ ratio and the initial static bed $\left(H_{s}\right)$ ratio increase.

\section{Numerical Optimization of Model}

In optimization, the possible goals are: maximize, minimize, target, within range, none (for responses only) and set to an exact value (factors only). A minimum and a maximum level must be provided for each parameter included in the optimization. If a response is transformed, the optimization will use either the original or transformed scale.

Desirability is an objective function that ranges from zero outside of the limits to one at the goal. The numerical optimization finds a point that maximizes the desirability function. The characteristics of a goal may be altered by adjusting the weight or importance. For several responses and factors, all goals get combined into one desirability function. The "importance" of each goal can be changed in relation to the other goals as shown in Table (4).

The optimum conditions that satisfy the minimum pressure drop of the bed with maximum desirability of 0.961 using 32 solutions run would be as shown in Table (5).

\section{Conclusion}

In the present work, the hydrodynamic behavior of two-phase fluidized bed of homogenous binary mixture has been carried out. The hydrodynamics of gas-solid fluidized beds were investigated using a BoxBehnken experimental design to determine the relationship between bed pressure drop and three independent factors: minimum fluidization superficial velocity $\left(U_{m f}\right)$, red mud to aluminum ratio $(R / A)$, and static head $(H s)$. Box-Behnken design allowed the development of second order polynomial equation $\left(R^{2}=0.9829\right)$, where bed pressure drop was assessed as a function of the independent factors and their interactions. The developed correlation can be effectively used for the prediction of bed pressure drop from the experimental data. Analysis of variance (ANOVA) was used for graphical analysis of data to obtain the interaction between factors and response. The model was validated by comparing the predicted response values from the models to the response experiment values of various binary mixture values.
With a $96 \%$ confidence level, the expected values obtained using the model equation was found to be in good agreement with the experimental values. Optimum conditions with the lowest bed pressure drop and the highest desirability of 0.961 were found using numerical optimization. For several responses and factors, all goals get combined into one desirability function of 0.961 that gives optimum factors of minimum bed pressure drop.

\section{References}

[1] J.F. Richardson, W.N. Zaki, Sedimentation and fluidisation: Part I, Chemical Engineering Research and Design, 75(1997) S82-S100. [DOI]

[2] M. Asif, A.A. Ibrahim, Minimum fluidization velocity and defluidization behavior of binarysolid liquid-fluidized beds, Powder Technology 12 (2002) 241-254. [DOI]

[3] P.D.S. de Vasconcelos, A.L.A. Mesquita, Minimum and full fluidization velocity for alumina used in the aluminum smelter, International Journal of Engineering Business Management 3(2011) 23-13. [DOl]

[4] K.C. Biswal, B.B. Samal, G.K. Roy, Dynamics of gas-solid fluidization of regular particles in conical vessels, Journal of the Institution of Engineers, 65(1984) 15-17.

[5] D.C. Sau, K.C. Biswal, Computational fluid dynamics and experimental study of the hydrodynamics of a gas-solid tapered fluidized bed, Applied Mathematical Modelling, 35 (2011) 2265-2278. [DOl]

[6] Gupta, S.K., Agarwal, V.K., Singh, S.N., V. Seshadri, D. Mills, J. Singh, C. Prakash, Prediction of minimum fluidization velocity for fine tailing material, Powder Technology, 196 (2009), 263-271. [DOI]

[7] S. Bhoi, Experimental and CFD Simulation Study of Binary Solid-Liquid Fluidized Bed, MTech thesis, (2009) National Institute of Technology, Rourkela.

[8] J.M. Valverde, A. Castellanos, Types of gas fluidization of cohesive granular materials, Physical Review E, 75(2007) 031306. [DOl]

[9] S. Sahoo, Fluidized bed reactor: design and application for abatement of fluoride, Rourkelta, BTech thesis, (2012) National Institute of Technology, Rourkela.

[10] D.C. Montgomery, Design and Analysis of Experiments, 6 ${ }^{\text {th }}$ Ed, (2005) John Wiley \& Sons, Inc., New York. 
[11] Khuri, S. Mukhopadhyay, Response Surface Methodology, WIREs Computational Statistics, 2 (2010) 128-149. [DOI]

[12] D.T.K. Dora, Y.K. Mohanty, G.K. Roy, Hydrodynamics of three-phase fluidization of a homogeneous ternary mixture of irregular particles, Chemical Engineering Science, 79(2012) 210-218. [DOl]

[13] D.T.K. Dora, Y.K. Mohanty, G.K. Roy, Hydrodynamics of three-phase fluidization of a homogeneous ternary mixture of regular particles-Experimental and statistical analysis, Powder Technology, 237(2013) 594-601. [DOI]

[14] A-T. Mohammad, A.S. Abdulhameed, A.H. Jawad, Box-Behnken design to optimize the synthesis of new crosslinked chitosan glycoxal/TiO2 nanocomposite: methyl orange absorption and mechanism studies, International journal of biological macromolecules, 129(2019) 98-109. [DOl]

[15] E. Zhou, Y. Zhang, Y. Zhao, Z. Luo, J. He, C.G. Duan, Characteristic gas velocity and fluidization quality evaluation of vibrated dense medium fluidized bed for fine coal separation, Advanced Powder Technology, 29(2018) 985995. [DOl]

\section{Acknowledgement}

The authors are gratefully acknowledged the Chemical Engineering Department, College of Engineering, Babylon University, Iraq for their help and assistance.

\section{Funding}

No funding was received for conducting this study.

\section{Conflict of interest}

The Author has no conflicts of interest to declare that they are relevant to the content of this article.

\section{Does this article screened for similarity?}

Yes

\section{About the License}

(C) The author 2021. The text of this article is open access and licensed under a Creative Commons Attribution 4.0 International License 